\title{
ASPECTOS AMBIENTAIS DA TRILHA VIA NOROESTE DO PARQUE ESTADUAL PICO DO MARUMBI, PR
}

\author{
Yury Vashchenko ${ }^{1}$, Daniela Biondi ${ }^{2}$, Marcelo Ricardo de Lima $^{3}$, Carlos Vellozo Roderjan ${ }^{4}$ \\ ${ }^{1}$ Eng. Florestal, Dr., Coordenadoria de Desenvolvimento Ambiental, FATMA, Mafra, SC, Brasil - vashchenko_01@yahoo.com.br \\ ${ }^{2}$ Eng ${ }^{a}$. Florestal, Dr ${ }^{\mathrm{a}}$., Depto. de Ciências Florestais, UFPR, Curitiba, PR, Brasil - dbiondi@ufpr.br \\ ${ }^{3}$ Eng. Agrônomo, Dr., Depto. de Solos e Engenharia Agrícola, UFPR, Curitiba, PR, Brasil - mrlima@ufpr.br \\ ${ }^{4}$ Eng. Florestal, Dr., Depto. de Ciências Florestais, UFPR, Curitiba, PR, Brasil - roderjan @ufpr.br
}

Recebido para publicação: 20/12/2012 - Aceito para publicação: 21/06/2013

\begin{abstract}
Resumo
O Parque Estadual Pico do Marumbi foi criado em 1990 com a finalidade de preservar o maciço Marumbi. A trilha Via Noroeste é um dos principais acessos ao Olimpo, ponto culminante do maciço, além de outros cumes do conjunto. Devido à visitação intensa e à ação da erosão, essa trilha apresenta pontos extremamente degradados. O objetivo foi caracterizar e classificar os solos e a vegetação e correlacioná-los com declividade, altitude, geologia e posição no relevo, gerando, assim, subsídio para posterior avaliação da erosão. Ao longo da trilha, foram realizadas tradagens e abertura de perfis para descrição geral e morfológica dos solos. A vegetação foi caracterizada fisionomicamente. Em seguida correlacionaram-se vegetação, solos, declividade, altitude, geologia e posição no relevo. Observou-se que predominou o granito Marumbi como material geológico. Foram identificados solos pertencentes às classes dos Cambissolos, Argissolos, Neossolos e Organossolos, e a cobertura vegetal foi classificada como Floresta Ombrófila Densa, subdividida nas formações Submontana, Submontana transição Montana, Montana, Montana de porte baixo, Altomontana e Altomontana de porte baixo. Concluiu-se que a altitude e a declividade definem os solos e a vegetação de acordo com a posição no relevo.

Palavras-chave: Ecologia florestal; solos florestais; vegetação de montanha.
\end{abstract}

\begin{abstract}
Environmental aspects of the Via Noroeste trail of the Pico do Marumbi State Park, PR. Pico do Marumbi State Park was created in 1990 to preserve the Marumbi massif. The Via Noroeste trail is one of the main access to Olimpo, the culmination point. This trail presents extremely degraded points, because the intense visitation and action of erosion. This research aim to characterize and classify the soils and vegetation and correlate them with slope, elevation, geology and position on the relief, in order to generate subsidy for future erosion assessment. Soil profiles were exposed for morphologic description. The vegetation was physionomically characterized. Then it correlated vegetation, soils, slope, altitude, geology and position on the relief. The Marumbi granite was identified as the geological predominant material. The soils were classified as Cambisols, Acrisols, Leptosols, Regosols and Histosols. The vegetation was classified as Dense Ombrophilous Forest (Rain Forest), subdivided in Submontane Forest, Submontane transition Montane Forest, Montane Forest, small sized Submontane Forest, Upper Montane Forest, small sized Upper Montane Forest and Grassland. As conclusion, the altitude and slope define soil and vegetation according to the position on the relief.
\end{abstract}

Keywords: Forestry ecology; Forestry soils; Mountain vegetation.

\section{INTRODUÇÃO}

A Serra do Mar é coberta pela Floresta Ombrófila Densa, na qual, de maneira geral, verifica-se, com o aumento da altitude, a mudança fisionômica, caracterizada pela diminuição do número de espécies, das dimensões das árvores e do número de estratos arbóreos (RODERJAN, 1994; BLUM, 2006; VASHCHENKO et al., 2007).

Os solos dessa área são geralmente rasos ou pouco profundos e apresentam elevada acidez, a qual é compatível com os altos índices de saturação por alumínio, sendo que os maiores valores ocorrem nas maiores altitudes. Observa-se, também, baixa saturação por bases, abaixo de 50\%, caracterizando 
solos distróficos. Além disso, com o aumento da altitude, é observado o aumento dos teores de carbono orgânico nos horizontes superficiais, o que representa uma maior quantidade de matéria orgânica, verificada pelo aumento da espessura da serapilheira (BLUM, 2006; VASHCHENKO et al., 2007).

O Parque Estadual Pico do Marumbi está localizado no município de Morretes, PR, abrangendo parte da Serra do Mar paranaense. O parque foi criado em 1990 e implantado em 1995, com a finalidade de proteger o Maciço Marumbi, que é constituído por vários cumes, os quais recebem denominações diferentes, sendo o Olimpo o ponto culminante, com $1.539 \mathrm{~m}$.

A trilha Via Noroeste é um dos principais acessos ao Olimpo, além de outros cumes do maciço. Devido à visitação intensa e à ação da erosão, essa trilha apresenta pontos extremamente degradados.

A erosão nas trilhas é influenciada pela intensidade de uso, classe de solo, vegetação e declividade, sendo que a erosão aumenta com o aumento do uso e da declividade, independentemente do solo e da vegetação (VASHCHENKO et al., 2008).

Portanto, caracterizar o ambiente - considerando os fatores vegetação, solo e relevo - onde a trilha está localizada é de extrema importância, pois esse conhecimento básico proporciona o entendimento da dinâmica desses fatores no ambiente e auxilia na identificação de suas fragilidades.

Considerando a hipótese de que a altitude e a declividade definem os solos e a vegetação de acordo com a posição no relevo, o objetivo foi caracterizar e classificar os solos e a vegetação e correlacioná-los com declividade, altitude, geologia e posição no relevo, gerando, assim, subsídio para posterior avaliação da erosão.

\section{MATERIAL E MÉTODOS}

\section{Caracterização da área de estudo}

O Parque Estadual Pico do Marumbi está localizado no município de Morretes, PR, entre as coordenadas geográficas $25^{\circ} 24^{\prime}$ e $25^{\circ} 31^{\prime}$ de latitude sul e $48^{\circ} 58^{\prime}$ e e $48^{\circ} 53^{\prime}$ de longitude oeste (Figura 1). Foi criado em 1990, com uma área equivalente a 2.342,4 ha (PARANÁ, 1990), localizada no município de Morretes, e ampliada para 8.745,4 ha em 2007 (PARANÁ, 2007), abrangendo os municípios de Morretes, Piraquara e Quatro Barras.

O maciço Marumbi é constituído por um bloco granítico, denominado de Granito Marumbi, originado há mais de 545 milhões de anos, no Pré-Cambriano, apresentando um relevo de falha, com vales profundos preenchidos por diques de diabásio, originados entre 65 e 206 milhões de anos, no Jurássico-Cretáceo. Ao lado desse maciço encontram-se, ainda, migmatitos, também do Pré-Cambriano, e Pedimentos remanescentes, originados entre 10 mil e 1,8 milhões de anos, no Pleistoceno (CORDANI; GIRARDI, 1967).
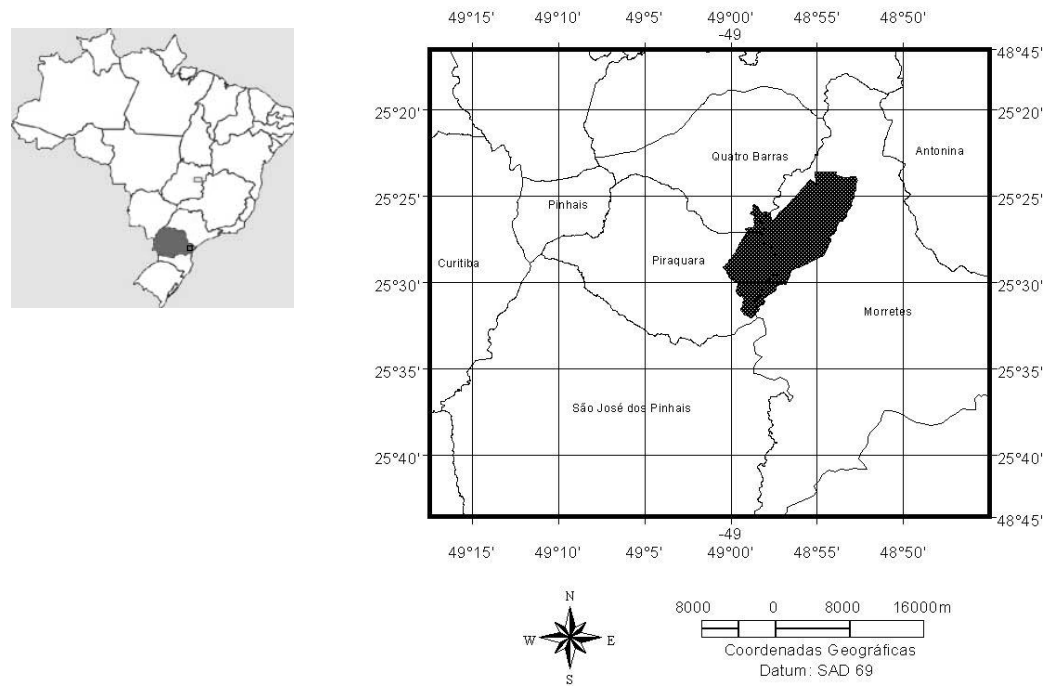

Figura 1. Localização Parque Estadual Pico do Marumbi.

Figure 1. Location of Pico do Marumbi State Park. 
A altitude varia entre 480 e $1.539 \mathrm{~m}$ s.n.m. e o relevo é escarpado predominantemente, com declividades que ultrapassam 75\% (SECRETARIA DE ESTADO DO MEIO AMBIENTE E RECURSOS HÍDRICOS (SEMA), 1996).

De acordo com a classificação de Köppen, ocorrem dois tipos climáticos - Cfa e Cfb. Nas porções inferiores a $700 \mathrm{~m}$ de altitude, ocorre o clima subtropical (Cfa), enquanto que nas partes mais elevadas ocorre o clima temperado mesotérmico $(\mathrm{Cfb})$ (INSTITUTO AGRONÔMICO DO PARANÁ (IAPAR), 2012).

Os solos são predominantemente pertencentes às classes dos Cambissolos e Neossolos, ocorrendo, também, afloramentos de rocha. Nas porções de menor declividade e altitude encontram-se solos mais profundos (Cambissolos) e nas porções de maior declive e solos rasos, os Neossolos, devido à maior perda de sedimentos, com muitos matacões, seixos e calhaus intercalados com solo. Os afloramentos de rocha ocorrem principalmente nos topos e nas porções com maior declividade (SECRETARIA ESTADUAL DO MEIO AMBIENTE E RECURSOS HÍDRICOS (SEMA), 1996).

O maciço Marumbi é coberto pela Floresta Ombrófila Densa, conhecida como Floresta Atlântica, a qual é subdividida nas formações Submontana, Montana e Altomontana, sendo que o cume denominado Boa Vista é coberto por Refúgio Vegetacional (SEMA, 2002).

\section{Procedimentos metodológicos}

As formações florestais foram previamente classificadas, em campo, pela altura do dossel, número de estratos e espécies indicadoras. Como pontos de controle, a cada $50 \mathrm{~m}$ de altitude foi realizada a descrição da vegetação.

Nesses pontos, a vegetação foi descrita considerando número, altura e cobertura dos estratos, amplitude diamétrica, diâmetro à altura do peito (DAP) e ocorrência de epífitas, lianas, gramíneas e espécies indicadoras (Arecaceae), além de ser classificada com base em Instituto Brasileiro de Geografia e Estatística (IBGE) (1992).

Com base em IBGE (1992) e incluindo adaptações, considerando a fisionomia, porte da vegetação e algumas espécies indicadoras, as formações florestais foram classificadas como Floresta Ombrófila Densa Submontana, Floresta Ombrófila Densa Submontana transição Montana, Floresta Ombrófila Densa Montana, Floresta Ombrófila Densa Montana de porte baixo, Floresta Ombrófila Densa Altomontana e Floresta Ombrófila Densa Altomontana de porte baixo.

Utilizaram-se as espécies Geonoma gamiova Barb. Rodr. e G. schottiana Mart. como indicadoras das formações florestais, as quais são de fácil reconhecimento e visualização no sub-bosque da floresta. G. gamiova ocorre na formação Submontana e G. schottiana ocorre na formação Montana, sendo que ambas ocorrem na transição entre Submontana e Montana. Na formação Altomontana não se verifica a ocorrência de nenhuma das espécies citadas.

Além da descrição da vegetação, foi indicada a altitude, a classe de solo e o relevo, considerando classe de declividade.

Para a caracterização dos solos, primeiramente foram efetuadas tradagens ao longo da trilha de acesso com um trado holandês, observando os diversos padrões de relevo, drenagem e vegetação. Posteriormente foram abertos perfis complementares para descrição geral (altitude, geologia, situação posição no relevo, relevo local, pedregosidade, rochosidade e vegetação atual) e morfológica (horizonte, espessura, transição, cor, textura e estrutura), conforme Santos et al. (2005), e coletadas amostras de solo para análise química e granulométrica.

As amostras de solo foram secas em estufa a $65^{\circ} \mathrm{C}$ por $48 \mathrm{~h}$ e peneiradas em malha de $2 \mathrm{~mm}$. As análises químicas $\left(\mathrm{Ca}^{2+}, \mathrm{Mg}^{2+}, \mathrm{K}^{+}\right.$e $\mathrm{Al}^{3+}$ trocáveis, acidez potencial $(\mathrm{H}+\mathrm{Al}), \mathrm{pH}$ em $\mathrm{H}_{2} \mathrm{O}$ e carbono orgânico) foram realizadas no Laboratório de Fertilidade do Solo do Departamento de Solos e Engenharia Agrícola da Universidade Federal do Paraná (DSEA/UFPR), conforme as metodologias descritas em IAPAR (1991), para determinar os teores de carbono orgânico, e em Marques e Motta (2003), para os demais teores. A análise granulométrica (areia grossa e fina, silte e argila total), determinada pelo método do densímetro, foi realizada no Laboratório de Física do Solo do DSEA/UFPR, conforme as metodologias descritas em Empresa Brasileira de Pesquisa Agropecuária (EMBRAPA) (2011).

Antes de realizar a análise granulométrica, houve a oxidação da matéria orgânica com $\mathrm{H}_{2} \mathrm{O}_{2}$ (a $5 \%$, diluído em água deionizada) nas amostras com teor de carbono orgânico acima de $50 \mathrm{~g} \cdot \mathrm{kg}^{-1}$. 
A partir dos resultados das análises químicas e físicas foram calculados os valores de soma de bases (SB), capacidade de troca de cátions (valor T), atividade de argila, saturação de bases (V\%) e saturação de alumínio (m), de acordo com EMBRAPA (2011).

Após a análise dos parâmetros físicos, químicos e a descrição geral e morfológica dos horizontes, os solos foram classificados de acordo com EMBRAPA (2006).

Posteriormente à caracterização do solo e da vegetação, houve a necessidade de fazer uma reclassificação que diferenciasse situações, pois, usando a classificação de EMBRAPA (2006), diferentes locais apresentaram a mesma classificação, não podendo, assim, serem comparados. Portanto, criou-se a classificação posição no relevo, como segue: a) encosta, a qual se subdivide em côncava, convexa e retilínea; b) crista; e c) cume.

De maneira geral, entende-se como crista um interflúvio relativamente estreito e longo entre duas encostas escarpadas, portanto, localizado nas porções mais elevadas, podendo ou não ligar dois cumes. O cume pode ser o ponto mais elevado encontrado em uma crista ou uma área isolada mais elevada, podendo apresentar feições arredondadas com declividades mais suaves em relação à encosta, que apresenta um relevo montanhoso a escarpado, com declividade de 45 a $75 \%$ e maior de $75 \%$, respectivamente (EMBRAPA, 2006) (Figura 2).

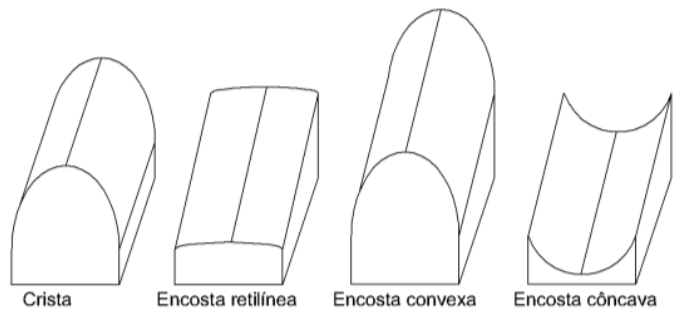

Figura 2. Representação esquemática da posição no relevo para caracterizar as trilhas do Parque Estadual do Pico Marumbi.

Figure 2. Schematic representation of the position on the relief to charatize the trail of Pico do Marumbi State Park.

A encosta côncava representou porções mais baixas entre dois interflúvios, chamados de vales, cujo relevo variou de forte ondulado a escarpado no sentido da pendente. As encostas convexa e retilínea representam os interflúvios, porém a encosta retilínea apresenta um relevo que varia de plano a forte ondulado (de 0 a $45 \%$ de declividade) no sentido da pendente e dos flúvios (rios). A encosta convexa representou um interflúvio estreito, com relevo suave ondulado de 2 a $5 \mathrm{~m}$ de largura no sentido transversal à pendente, seguido de relevo escarpado em direção aos flúvios. No sentido da pendente apresenta um relevo de montanhoso a escarpado (Figura 2).

Para correlacionar os solos, vegetação, declividade e posição no relevo, utilizaram-se alguns métodos de análise estatística multivariada (análise de componentes principais e correlação de dados de Pearson). Com a correlação de dados, avaliou-se a correlação entre os dados levantados sobre a fisionomia vegetação. Com a análise de componentes principais, avaliaram-se as relações entre os solos e a vegetação com a altitude, a declividade, a posição no relevo e a geologia, considerando ainda rochosidade e pedregosidade. Para as análises estatísticas, utilizou-se o programa computacional estatístico Statigraphics Centurion plus XV.

\section{RESULTADOS E DISCUSSÃO}

\section{Solos}

Foram caracterizadas 13 classes de solo nessa trilha (2 Cambissolos, 7 Neossolos, 1 Argissolo, 3 Organossolos). Os solos são bem drenados e na maioria são rochosos, porém não pedregosos. Onde a floresta tem maior porte, ocorre uma ligeira erosão laminar; nos demais, a erosão não é aparente (Tabela 1).

De maneira geral, os solos são rasos $(<50 \mathrm{~cm})$ ou pouco profundos (de 50 a $100 \mathrm{~cm})$, sendo alguns profundos (de 100 a $200 \mathrm{~cm}$ ) (Tabela 2). Essa pouca profundidade também em ambiente 
altomontano foi observada por Vashchenko et al. (2007). Isso se deve à posição no relevo e declividade. Rossi e Queiroz Neto (2001) mencionam, além desses fatores, os altos índices pluviométricos como condição para a existência de solos rasos em regiões montanhosas.

Além de rasos, os solos apresentam elevada acidez, com variação no pH em água de 3,2 a 4,9 (Tabela 2). Valores de pH semelhantes foram observados por outros autores, como Dias et al. (2003) e Benites et al. (2003). Valores de $\mathrm{pH}$ abaixo de 4,5 definem solos como extremamente ácidos.

A elevada acidez está relacionada com os índices de saturação por alumínio, que variam de zero a 94\%, predominando valores acima de 80\%. Dias et al. (2003), Vashchenko et al. (2007) e Scheer et al. (2011) também encontraram valores semelhantes.

Aliado à elevada acidez e saturação de alumínio, observa-se a predominância de solos distróficos com baixa saturação por bases, com variação de 1 a 50\%. O Neossolo Litólico Eutrófico típico apresentou a maior saturação por bases entre os solos encontrados, sendo $22 \%$ no horizonte A e $50 \%$ no horizonte $\mathrm{AC}$, o que lhe confere o caráter eutrófico. Nos demais solos, a saturação por bases não ultrapassou $15 \%$. Ghani (1996), Dias et al. (2003), Vashchenko et al. (2007) e Scheer et al. (2011) também observaram baixa saturação por bases, não ultrapassando $38 \%$.

Com relação aos teores de carbono orgânico nos horizontes dos solos estudados, observa-se uma variação de 18 a 401 g.kg ${ }^{-1}$. Os horizontes classificados como orgânicos apresentaram teores de carbono orgânico entre 229 e $401 \mathrm{~g} \cdot \mathrm{kg}^{-1}$, enquanto que os horizontes minerais apresentaram teores entre $18 \mathrm{e}$

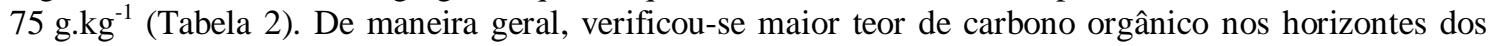
solos nas maiores altitudes, sendo maior nos horizontes mais superficiais. Esse mesmo comportamento foi observado por Benites et al. (2003) e Vashchenko et al. (2007).

Em relação à fração mineral (areia, silte e argila), observa-se o predomínio de areia grossa e argila, sobre areia fina e silte, sendo que a argila predomina nos Cambissolos, enquanto que a areia grossa predomina nos Neossolos. Os horizontes dos solos apresentaram, em média, 300 g. $\mathrm{kg}^{-1}$ de areia grossa e $340 \mathrm{~g} \cdot \mathrm{kg}^{-1}$ de argila, sendo que em alguns casos esses valores ultrapassaram $500 \mathrm{~g} \cdot \mathrm{kg}^{-1}$. Em relação à areia fina e ao silte, os horizontes dos solos apresentaram em média 80 e $150 \mathrm{~g}^{\mathrm{kg}} \mathrm{kg}^{-1}$ de solo, respectivamente. Já nos Organossolos, predomina matéria orgânica na composição dos solos.

Os Cambissolos apresentaram os horizontes $\mathrm{A}, \mathrm{Bi}$ e $\mathrm{C}$, sendo a presença do horizonte $\mathrm{B}$ incipiente o que determina a classificação de Cambissolo. A espessura desses solos variou de 75 a 130 $\mathrm{cm}$, aproximadamente, sendo classificados como pouco profundos, com espessura entre 50 e $100 \mathrm{~cm}$, a profundos, com espessura entre 100 e $200 \mathrm{~cm}$.

Um perfil foi classificado como Argissolo, o qual apresentou os horizontes $\mathrm{O}, \mathrm{A}, \mathrm{Bt}$ e $\mathrm{C}$, sendo a presença do horizonte $\mathrm{B}$ textural o que determina a classificação de Argissolo. A profundidade média desse solo foi de $138 \mathrm{~cm}$, sendo classificado como profundo, tendo o horizonte $\mathrm{O} 35 \mathrm{~cm}$ de espessura.

Os Neossolos apresentaram o horizonte A ou A e AC, assentes sobre rocha (camada R), sem horizonte B diagnóstico, o que determina a sua classificação. A profundidade variou de 23 a $108 \mathrm{~cm}$, com presença do horizonte orgânico de até $20 \mathrm{~cm}$ nos solos localizados nas maiores altitudes. Devido à profundidade, os Neossolos foram divididos em Litólicos, com profundidade menor que $50 \mathrm{~cm}$, e Regolíticos, com profundidade acima desse valor. Eles estão localizados em encosta côncava (vales), de relevo suave ondulado a ondulado sobre migmatito e de relevo escarpado sobre dique de diabásio, em encosta convexa de relevo montanhoso a escarpado sobre cone detrítico e em encosta côncava e convexa de relevo ondulado a escarpado sobre granito. Uma característica muito marcante nesses locais é a mescla dos solos com matacões, conferindo elevada pedregosidade e rochosidade.

Dois solos apresentaram os horizontes A e AC e os demais, horizonte A, sendo que os solos com horizonte A húmico apresentaram horizonte orgânico de 7 a $30 \mathrm{~cm}$ (Tabela 2).

Conforme EMBRAPA (2006), os Organossolos são solos constituídos por material orgânico, apresentando horizonte hístico com teor de matéria orgânica maior ou igual a $80 \mathrm{~g} \cdot \mathrm{kg}^{-1}$. Na área de estudo, esses solos apresentaram horizonte hístico em diferentes graus de decomposição (classificados como sáprico, com maior grau de decomposição, e hêmico, com menor grau de decomposição), assentes diretamente sobre rocha ou assentes em horizonte $\mathrm{Cg}$ sobre rocha, predominando solos com a presença do horizonte $\mathrm{Cg}$.

A profundidade desses solos variou de 22 a $30 \mathrm{~cm}$, sendo que a espessura do horizonte $\mathrm{Cg}$ variou de 5 a $20 \mathrm{~cm}$. 
Tabela 1. Descrição geral dos perfis dos solos (altitude, geologia, situação, relevo local, pedregosidade, rochosidade, vegetação atual, drenagem, erosão) na trilha Via Noroeste, Parque Estadual Pico do Marumbi.

Table 1. General description of soils profiles (altitude, geology, situation, local relief, stone, rock, present vegetation, drainage, erosion) in Via Noroeste trail, Pico do Marumbi State Park.

\begin{tabular}{|c|c|c|c|c|c|c|c|}
\hline Altitude (m) & Geologia & Situação & Relevo local & $\begin{array}{c}\text { Pedregosidade e } \\
\text { rochosidade }\end{array}$ & $\begin{array}{c}\text { Vegetação } \\
\text { atual }\end{array}$ & Drenagem & Erosão \\
\hline \multicolumn{8}{|c|}{ P01 N - Neossolo Litólico Distrófico coluvionar A moderado textura argilosa (RLd5) } \\
\hline 520 & $\begin{array}{c}\text { Granito } \\
\text { Marumbi }\end{array}$ & $\begin{array}{l}\text { Encosta } \\
\text { côncava }\end{array}$ & Ondulado & EP e R & $\begin{array}{l}\text { FODS } \\
\text { SSInt }\end{array}$ & $\begin{array}{c}\text { Bem } \\
\text { drenado }\end{array}$ & $\begin{array}{c}\text { Não } \\
\text { aparente }\end{array}$ \\
\hline \multicolumn{8}{|c|}{ P02 N - Cambissolo Háplico Tb Distrófico típico A moderado textura argilosa (CXbd6) } \\
\hline 550 & $\begin{array}{c}\text { Granito } \\
\text { Marumbi }\end{array}$ & $\begin{array}{l}\text { Encosta } \\
\text { retilínea }\end{array}$ & $\begin{array}{c}\text { Forte } \\
\text { ondulado }\end{array}$ & NP e NR & FODS & $\begin{array}{c}\text { Bem } \\
\text { drenado }\end{array}$ & $\begin{array}{c}\text { Laminar } \\
\text { ligeira }\end{array}$ \\
\hline \multicolumn{8}{|c|}{ P03 N - Cambissolo Háplico Tb Distrófico léptico A moderado textura argilosa (CXbd7) } \\
\hline 600 & $\begin{array}{l}\text { Granito } \\
\text { Marumbi }\end{array}$ & $\begin{array}{l}\text { Encosta } \\
\text { retilínea }\end{array}$ & $\begin{array}{c}\text { Forte } \\
\text { ondulado }\end{array}$ & NP e R & FODS & $\begin{array}{l}\text { Bem } \\
\text { drenado }\end{array}$ & $\begin{array}{c}\text { Laminar } \\
\text { ligeira }\end{array}$ \\
\hline \multicolumn{8}{|c|}{ P04 N - Neossolo Litólico Eutrófico típico A moderado textura argilosa (RLe) } \\
\hline 662 & $\begin{array}{c}\text { Não } \\
\text { identificad } \\
\text { a } \\
\end{array}$ & $\begin{array}{l}\text { Encosta } \\
\text { convexa }\end{array}$ & Escarpado & NP e NR & FODS & $\begin{array}{l}\text { Bem } \\
\text { drenado }\end{array}$ & $\begin{array}{l}\text { Laminar } \\
\text { ligeira }\end{array}$ \\
\hline \multicolumn{8}{|c|}{ P05 N - Neossolo Litólico Húmico coluvionar textura franca (RLh4) } \\
\hline 745 & $\begin{array}{l}\text { Cone } \\
\text { detrítico }\end{array}$ & $\begin{array}{l}\text { Encosta } \\
\text { retilínea }\end{array}$ & Escarpado & LP e R & $\begin{array}{l}\text { FODS } \\
\text { (trans) e } \\
\text { FODM } \\
\end{array}$ & $\begin{array}{l}\text { Bem } \\
\text { drenado }\end{array}$ & $\begin{array}{l}\text { Não } \\
\text { aparente }\end{array}$ \\
\hline \multicolumn{8}{|c|}{ P06 N - Organossolo Fólico Hêmico lítico térrico textura orgânica fíbrica (OOy2) } \\
\hline 950 & $\begin{array}{c}\text { Granito } \\
\text { Marumbi }\end{array}$ & $\begin{array}{l}\text { Encosta } \\
\text { retilínea }\end{array}$ & Escarpado & NP e R & $\begin{array}{c}\text { FODM }(\mathrm{pb}) \\
\text { e FODA }\end{array}$ & $\begin{array}{c}\text { Bem } \\
\text { drenado }\end{array}$ & $\begin{array}{c}\text { Não } \\
\text { aparente }\end{array}$ \\
\hline \multicolumn{8}{|c|}{ P07 N - Neossolo Litólico Húmico típico coluvionar franco argilo arenosa (RLh5) } \\
\hline 1030 & $\begin{array}{l}\text { Granito } \\
\text { Marumbi }\end{array}$ & $\begin{array}{l}\text { Encosta } \\
\text { côncava }\end{array}$ & Montanhoso & EP e R & $\begin{array}{l}\text { FODM, } \\
\text { FODM }(\mathrm{pb}) \\
\text { e FODA }\end{array}$ & $\begin{array}{l}\text { Bem } \\
\text { drenado }\end{array}$ & $\begin{array}{l}\text { Laminar } \\
\text { ligeira }\end{array}$ \\
\hline \multicolumn{8}{|c|}{ P08 N - Neossolo Litólico Húmico típico textura franco-argilosa (RLh6) } \\
\hline 1.140 & $\begin{array}{l}\text { Granito } \\
\text { Marumbi }\end{array}$ & $\begin{array}{l}\text { Encosta } \\
\text { convexa }\end{array}$ & Escarpado & LP e R & FODA & $\begin{array}{l}\text { Bem } \\
\text { drenado }\end{array}$ & $\begin{array}{c}\text { Não } \\
\text { aparente }\end{array}$ \\
\hline \multicolumn{8}{|c|}{ P09 N - Neossolo Litólico Húmico fragmentário textura franco-argilo-arenosa (RLh7) } \\
\hline 1.210 & $\begin{array}{l}\text { Dique de } \\
\text { Diabásio }\end{array}$ & Côncava & Escarpado & $\mathrm{EP}$ e $\mathrm{M}_{2} \mathrm{R}$ & FODA & $\begin{array}{c}\text { Bem } \\
\text { drenado }\end{array}$ & $\begin{array}{c}\text { Laminar } \\
\text { ligeira }\end{array}$ \\
\hline \multicolumn{8}{|c|}{ P10 N - Argissolo Amarelo Alítico Epiáquico (PAal) } \\
\hline 1.327 & $\begin{array}{l}\text { Granito } \\
\text { Marumbi }\end{array}$ & Crista & Escarpado & NP e NR & FODA & $\begin{array}{c}\text { Bem } \\
\text { drenado }\end{array}$ & $\begin{array}{c}\text { Não } \\
\text { aparente }\end{array}$ \\
\hline \multicolumn{8}{|c|}{ P11 N - Organossolo Fólico Hêmico lítico térrico textura orgânica fíbrica (OOy3) } \\
\hline 1.463 & $\begin{array}{l}\text { Granito } \\
\text { Marumbi }\end{array}$ & $\begin{array}{c}\text { Crista } \\
\text { (Gigante) }\end{array}$ & $\begin{array}{c}\text { Forte } \\
\text { ondulado e } \\
\text { escarpado }\end{array}$ & NP e R & $\begin{array}{l}\text { FODA e } \\
\text { FODA (pb) }\end{array}$ & $\begin{array}{l}\text { Bem } \\
\text { drenado }\end{array}$ & $\begin{array}{c}\text { Não } \\
\text { aparente }\end{array}$ \\
\hline \multicolumn{8}{|c|}{ P12 N - Neossolo Regolítico Húmico léptico textura franco arenosa (RRh) } \\
\hline 1.000 & $\begin{array}{c}\text { Granito } \\
\text { Marumbi }\end{array}$ & $\begin{array}{l}\text { Encosta } \\
\text { retilínea }\end{array}$ & Escarpado & NP e LR & FODA & $\begin{array}{l}\text { Bem } \\
\text { drenado }\end{array}$ & $\begin{array}{c}\text { Não } \\
\text { aparente }\end{array}$ \\
\hline \multicolumn{8}{|c|}{ P13 N - Organossolo Fólico Hêmico lítico térrico textura orgânica fíbrica (OOy4) } \\
\hline 1.199 & $\begin{array}{l}\text { Granito } \\
\text { Marumbi }\end{array}$ & $\begin{array}{c}\text { Crista } \\
\text { (Abrolhos) }\end{array}$ & Escarpado & $\mathrm{NP}$ e $\mathrm{M}_{2} \mathrm{R}$ & FODA(pb) & $\begin{array}{c}\text { Bem } \\
\text { drenado }\end{array}$ & $\begin{array}{c}\text { Não } \\
\text { aparente }\end{array}$ \\
\hline
\end{tabular}

Nota: D: declividade; Pedregosidade: NP: não pedregosa, LP: ligeiramente pedregosa, $\mathrm{M}_{1} \mathrm{P}$ : moderadamente pedregosa, $\mathrm{M}_{2} \mathrm{P}$ : muito pedregosa, EP: extremamente pedregosa; Rochosidade: NR: não rochosa, LR: ligeiramente rochosa, $M_{1} R$ : moderadamente rochosa, $\mathrm{R}$ : rochosa, $\mathrm{M}_{2} \mathrm{P}$ : muito rochosa; Vegetação atual: FODS: Floresta Ombrófila Densa Submontana, FODM: Floresta Ombrófila Densa Montana, FODM (pb): Floresta Ombrófila Densa Montana de porte baixo, FODA: Floresta Ombrófila Densa Altomontana, FODA (pb): Floresta Ombrófila Densa Altomontana de porte baixo, trans: transição, SSInt: Sucessão Secundária Intermediária. 
Tabela 2. Espessura, carbono (C) orgânico, teores de areia, argila, silte, $\mathrm{pH}$ em $\mathrm{H}_{2} \mathrm{O}$, saturação por bases (V) e saturação de alumínio (m) de cada horizonte dos solos na trilha Via Noroeste, Parque Estadual Pico do Marumbi.

Table 2. Thickness, organic carbon, sand, clay and silt content, $\mathrm{pH}$ in $\mathrm{H}_{2} \mathrm{O}$, basis saturation, aluminum saturation of each soil horizon in Via Noroeste trail, Pico do Marumbi State Park.

\begin{tabular}{|c|c|c|c|c|c|c|c|c|c|}
\hline \multirow[b]{2}{*}{ Horizonte } & \multirow{2}{*}{$\begin{array}{l}\text { Espessura } \\
\text { (cm) }\end{array}$} & \multirow{2}{*}{$\begin{array}{c}\text { C orgânico } \\
\left(\text { g.kg }^{-1}\right)\end{array}$} & \multicolumn{4}{|c|}{ Composição ganulométrica da terra fina $\left({\mathrm{g} . \mathrm{kg}^{-1}}^{-1}\right)$} & \multirow[b]{2}{*}{$\begin{array}{c}\text { pH em } \\
\mathrm{H}_{2} \mathrm{O}\end{array}$} & \multirow[t]{2}{*}{$\mathbf{V}$} & \multirow[t]{2}{*}{$\mathbf{m}$} \\
\hline & & & $\begin{array}{c}\text { Areia } \\
\text { grossa }\end{array}$ & $\begin{array}{c}\text { Areia } \\
\text { fina }\end{array}$ & Silte & Argila & & & \\
\hline \multicolumn{10}{|c|}{ P01 N - Neossolo Litólico Distrófico coluvionar A moderado textura argilosa (RLd5) } \\
\hline Oo & 2 & - & - & - & - & - & - & - & - \\
\hline A & 23 & 43 & 83 & 62 & 364 & 417 & 3,5 & 14,12 & 55,44 \\
\hline \multicolumn{10}{|c|}{ P02 N - Cambissolo Háplico Tb Distrófico típico A moderado textura argilosa (CXbd6) } \\
\hline Oo & 4 & - & - & - & - & - & - & - & - \\
\hline Od & 3 & - & - & - & - & - & - & - & - \\
\hline A & 15 & 25,8 & 266 & 63 & 151 & 480 & 3,4 & 5,94 & 83,2 \\
\hline $\mathrm{Bi}$ & 85 & 22,9 & 223 & 73 & 45 & 620 & 3,5 & 3,31 & 88,24 \\
\hline $\mathrm{C}$ & 30 & - & - & - & - & - & - & - & - \\
\hline \multicolumn{10}{|c|}{ P03 N - Cambissolo Háplico Tb Distrófico léptico A moderado textura argilosa (CXbd7) } \\
\hline Oo & 2 & - & - & - & - & - & & & \\
\hline A & 20 & 43 & 264 & 69 & 83 & 509 & 3,7 & 4,02 & 87,57 \\
\hline $\mathrm{Bi}$ & 50 & 24,3 & 201 & 63 & 62 & 632 & 4,1 & 4,76 & 83,97 \\
\hline $\mathrm{C}$ & 15 & 18,6 & 230 & 64 & 83 & 590 & 4,1 & 4,99 & 83,67 \\
\hline \multicolumn{10}{|c|}{ P04 N - Neossolo Litólico Eutrófico típico A moderado textura argilosa (RLe) } \\
\hline Oo & 2 & - & - & - & - & - & - & - & - \\
\hline Od & 4 & - & - & - & - & - & - & - & - \\
\hline A & 17 & 30,1 & 211 & 111 & 152 & 474 & 4,1 & 22,08 & 35,19 \\
\hline $\mathrm{AC}$ & 25 & 25,8 & 155 & 99 & 128 & 573 & 4,9 & 50,06 & 0 \\
\hline \multicolumn{10}{|c|}{ P05 N - Neossolo Litólico Húmico coluvionar textura franca (RLh4) } \\
\hline Oo & 2 & - & - & - & - & - & & & \\
\hline Od & 10 & - & - & - & - & - & - & - & - \\
\hline A & 35 & 57,3 & 197 & 155 & 369 & 180 & 3,5 & 3,6 & 84,43 \\
\hline \multicolumn{10}{|c|}{ P06 N - Organossolo Fólico Hêmico lítico térrico textura orgânica fíbrica (OOy2) } \\
\hline Oo & 4 & - & - & - & - & - & - & - & - \\
\hline Od & 10 & 229,1 & 239 & 59 & 213 & 94 & 3,5 & 9,21 & 53,45 \\
\hline $\mathrm{Cg}$ & 16 & - & - & - & - & - & - & - & - \\
\hline \multicolumn{10}{|c|}{ P07 N - Neossolo Litólico Húmico típico coluvionar franco-argilo-arenosa (RLh5) } \\
\hline Oo & 2 & - & - & - & - & - & - & - & - \\
\hline Od & 5 & - & - & - & - & - & - & - & - \\
\hline A & 30 & 74,5 & 427 & 50 & 77 & 318 & 3,8 & 3,01 & 87,98 \\
\hline \multicolumn{10}{|c|}{ P08 N - Neossolo Litólico Húmico típico textura franco-argilosa (RLh6) } \\
\hline Oo & 2 & - & - & - & - & - & - & - & - \\
\hline Od & 5 & - & - & - & - & - & - & - & - \\
\hline A & 50 & 48,7 & 393 & 44 & 135 & 344 & 4 & 4,46 & 84,64 \\
\hline \multicolumn{10}{|c|}{ P09 N - Neossolo Litólico Húmico fragmentário textura franco-argilo-arenosa (RLh7) } \\
\hline Oo & 3 & - & - & - & - & - & - & - & - \\
\hline A & 30 & 43 & 351 & 109 & 179 & 287 & 4,1 & 2,6 & 93,58 \\
\hline \multicolumn{10}{|c|}{ P10 N - Argissolo Amarelo Alítico Epiáquico (PAal) } \\
\hline Oo & 2 & - & - & - & - & - & - & - & - \\
\hline Od & 35 & 300,7 & 138 & 35 & 223 & 84 & 3,5 & 2,65 & 76,29 \\
\hline
\end{tabular}




\begin{tabular}{|c|c|c|c|c|c|c|c|c|c|}
\hline$E$ & 5 & - & - & - & - & - & - & - & - \\
\hline $\mathrm{Bt}$ & 66 & 34,4 & 11 & 5 & 223 & 701 & 3,7 & 3,72 & 91,98 \\
\hline $\mathrm{Cg}$ & 30 & - & - & - & - & - & - & - & - \\
\hline \multicolumn{10}{|c|}{ P11 N - Organossolo Fólico Hêmico lítico térrico textura orgânica fíbrica (OOy3) } \\
\hline Oo & 2 & - & - & - & - & - & - & - & - \\
\hline $\mathrm{Od}_{1}$ & 20 & 400,9 & 2 & 0 & 183 & 124 & 4,4 & 5,47 & 52,31 \\
\hline $\mathrm{Od}_{2}$ & 3 & 272 & 55 & 1 & 369 & 106 & 3,3 & 1,51 & 91,39 \\
\hline $\mathrm{Cg}$ & 5 & - & - & - & - & - & - & - & - \\
\hline \multicolumn{10}{|c|}{ P12 N - Neossolo Regolítico Húmico léptico textura franco-arenosa (RRh) } \\
\hline Oo & 10 & - & - & - & - & - & - & - & - \\
\hline Od & 20 & - & - & - & - & - & - & - & - \\
\hline A & 12 & 77,3 & 536 & 72 & 168 & 91 & 3,2 & 4,05 & 73,39 \\
\hline $\mathrm{AC}$ & 66 & 74,5 & 221 & 20 & 234 & 397 & 3,5 & 3,23 & 88,45 \\
\hline \multicolumn{10}{|c|}{ P13 N - Organossolo Fólico Hêmico lítico térrico textura orgânica fíbrica (OOy4) } \\
\hline Oo & 7 & - & - & - & - & - & - & - & - \\
\hline Od & 10 & 214,8 & 469 & 95 & 31 & 35 & 3,6 & 3,95 & 87,97 \\
\hline $\mathrm{Cg}$ & 5 & - & - & - & - & - & - & - & - \\
\hline
\end{tabular}

Os solos das maiores altitudes e menores declividades apresentaram as maiores profundidades (Tabela 2). Esses solos ocorreram em cristas, cumes, encostas côncavas e convexas de relevo montanhoso a escarpado, sobre migmatito, dique de diabásio e principalmente sobre granito.

\section{Vegetação}

Em relação à vegetação, na tabela 3 pode ser verificada a classificação da vegetação encontrada ao longo das trilhas e suas principais características identificadas. A Floresta Ombrófila Densa Submontana foi a mais desenvolvida, a qual apresenta maior altura do dossel, número de estratos e DAP, e a Floresta Ombrófila Densa Altomontana de porte baixo, a menos desenvolvida, com menor altura do dossel, número de estratos e DAP, configurando porte arbustivo mesclado com afloramentos de rochas.

De maneira geral, a altura do dossel variou de 1,5 a $16 \mathrm{~m}$ de altura, passando de porte arbóreo a arbustivo, de acordo com a mudança do relevo e do aumento da altitude. O número de estratos variou de 2 a 4, sendo que, quanto maior a altura do dossel, maior o número de estratos. O DAP máximo encontrado variou de 10 a $65 \mathrm{~cm}$, com amplitude diamétrica variando de pequena a média. Os maiores DAPs foram encontrados nas formações florestais com maior altura do dossel (Tabela 3).

O primeiro estrato, o sub-bosque, constituiu-se de plantas de até 1,0 m de altura, sendo elas a regeneração natural das arbóreas, bromeliáceas e demais herbáceas, enquanto que o segundo estrato incluiu espécies arbóreas de até $5 \mathrm{~cm}$ de diâmetro e de 3,5 a 5,0 $\mathrm{m}$ de altura. Já o terceiro estrato constituise por espécies arbóreas com diâmetro de 5 a $40 \mathrm{~cm}$ e altura de 5 a $10 \mathrm{~m}$, e o quarto estrato incluiu espécies arbóreas, codominantes e dominantes, com diâmetros que variaram de 40 a $65 \mathrm{~cm}$ e altura entre 10 e $16 \mathrm{~m}$.

A espécie indicadora Geonoma gamiova foi encontrada na formação Submontana (até $720 \mathrm{~m}$ de altitude - considerada limite para essa formação neste trabalho), enquanto que a $G$. schottiana foi encontrada na formação Montana (entre 790 e 930 m de altitude). Ambas foram encontradas numa faixa de aproximadamente $700 \mathrm{~m}$ de altitude, sendo a formação classificada como Submontana transição Montana (entre 720 a $790 \mathrm{~m}$ ). Acima dos $930 \mathrm{~m}$ de altitude não foi observada a presença de nenhuma das espécies citadas, sendo a formação classificada como Altomontana. A formação Montana de porte baixo se diferencia da Montana pela menor altura do dossel, e da formação Altomontana pela presença de $G$. schottiana.

$\mathrm{Na}$ tabela 4 se verifica a correlação entre o número, altura e cobertura dos estratos, com a ocorrência de epífitas, lianas e gramíneas, amplitude diamétrica e DAP. Observa-se que, quanto maior a altura do dossel, maior o número de estratos, estando eles correlacionados com o aumento do diâmetro das árvores (DAP) e de sua amplitude diamétrica. A presença de lianas tem correlação direta com esses dados, que indicam uma vegetação mais desenvolvida. 
Tabela 3. Classificação da vegetação, altura do dossel, número de estratos, maior DAP e espécies indicadoras na trilha Via Noroeste, Parque Estadual Pico do Marumbi.

Table 3. Classification of vegetation, height canopy, number stratum, higher BHD, and indicator species on Via Noroeste tail of Pico do Marumbi State Park.

\begin{tabular}{lcccc}
\hline Floresta & $\begin{array}{c}\text { Altura } \\
\text { estimada do } \\
\text { dossel (m) }\end{array}$ & $\begin{array}{c}\text { Número } \\
\text { de } \\
\text { estratos }\end{array}$ & $\begin{array}{c}\text { Maior } \\
\text { DAP } \\
(\mathbf{c m})\end{array}$ & Espécie indicadora \\
\hline Ombrófila Densa Submontana & 14 a 16 & 4 & 65 & Geonoma gamiova \\
Ombrófila Densa Submontana transição & 10 a 12 & 4 & 50 & G. gamiova e G. schottiana \\
Montana & 7 a 10 & 4 & 60 & Geonoma schottiana \\
Ombrófila Densa Montana & 2 a 6 & 3 & 20 & Geonoma schottiana \\
Ombrófila Densa Montana de porte baixo & 4 a 6 & 3 & 25 & - \\
Ombrófila Densa Altomontana & $<4$ & 2 & 10 & - \\
Ombrófila Densa Altomontana de porte baixo & & & & - \\
\hline
\end{tabular}

Tabela 4. Correlação entre número de estratos, altura do dossel, altura dos estratos, cobertura dos estratos, lianas, epífitas, gramíneas, amplitude diamétrica e diâmetro à altura do peito das diferentes formações vegetais encontradas na trilha Via Noroeste, Parque Estadual Pico do Marumbi.

Table 4. Correlation among stratum number, height canopy, stratum cover, lianas, epiphytes, grass, diametric amplitude and diameter at breast height of the differents vegetal formation found in Via Noroeste trail, Pico do Marumbi State Park.

\begin{tabular}{|c|c|c|c|c|c|c|c|c|c|c|c|c|c|c|c|}
\hline & NE & ADO & AE1 & AE2 & AE3 & AE4 & CE1 & CE2 & CE3 & CE4 & EP & $\mathbf{L}$ & G & AD & DAP \\
\hline $\mathrm{NE}$ & 1 & & & & & & & & & & & & & & \\
\hline $\mathrm{ADO}$ & 0,92 & 1 & & & & & & & & & & & & & \\
\hline $\mathrm{AE} 1$ & $-0,51$ & $-0,47$ & 1 & & & & & & & & & & & & \\
\hline AE2 & $\mathbf{0 , 9 0}$ & $\mathbf{0 , 9 8}$ & $-0,48$ & 1 & & & & & & & & & & & \\
\hline AE3 & 0,90 & $\mathbf{0 , 9 8}$ & $-0,44$ & 1,00 & 1 & & & & & & & & & & \\
\hline AE4 & $\mathbf{0 , 8 8}$ & $\mathbf{0 , 9 4}$ & $-0,29$ & $\mathbf{0 , 9 1}$ & $\mathbf{0 , 9 1}$ & 1 & & & & & & & & & \\
\hline CE1 & $-0,38$ & $-0,22$ & 0,45 & $-0,20$ & $-0,22$ & $-0,10$ & 1 & & & & & & & & \\
\hline CE2 & 0,34 & 0,21 & $-0,48$ & 0,24 & 0,25 & 0,07 & $-0,57$ & 1 & & & & & & & \\
\hline CE3 & 0,49 & 0,34 & $-0,44$ & 0,24 & 0,23 & 0,25 & $-0,45$ & 0,14 & 1 & & & & & & \\
\hline CE4 & $\mathbf{0 , 8 9}$ & $\mathbf{0 , 7 9}$ & $-0,29$ & $\mathbf{0 , 7 9}$ & $\mathbf{0 , 7 9}$ & 0,84 & $-0,22$ & 0,25 & 0,20 & 1 & & & & & \\
\hline EP & 0,67 & 0,41 & $-0,49$ & $\mathbf{0 , 4 0}$ & 0,38 & $\mathbf{0 , 4 0}$ & $-0,40$ & 0,22 & $\mathbf{0 , 8 1}$ & 0,47 & 1 & & & & \\
\hline $\mathrm{L}$ & 0,96 & $\mathbf{0 , 8 8}$ & $-0,31$ & 0,85 & $\mathbf{0 , 8 5}$ & 0,92 & $-0,20$ & 0,19 & 0,34 & $\mathbf{0 , 9 3}$ & $\mathbf{0 , 5 8}$ & 1 & & & \\
\hline G & $-0,55$ & $-0,57$ & 0,00 & $-0,61$ & $-0,61$ & $-0,70$ & $-0,06$ & 0,13 & 0,31 & $-0,78$ & $-0,02$ & $-0,68$ & 1 & & \\
\hline $\mathrm{AD}$ & $\mathbf{0 , 8 2}$ & $\mathbf{0 , 8 8}$ & $-0,27$ & $\mathbf{0 , 9 0}$ & $\mathbf{0 , 9 0}$ & $\mathbf{0 , 9 2}$ & $-0,04$ & 0,13 & 0,13 & $\mathbf{0 , 7 3}$ & 0,39 & $\mathbf{0 , 8 6}$ & $-0,68$ & 1 & \\
\hline DAP & 0,91 & $\mathbf{0 , 9 3}$ & $-0,43$ & 0,96 & $\mathbf{0 , 9 5}$ & 0,91 & $-0,20$ & 0,25 & 0,24 & $\mathbf{0 , 8 8}$ & 0,44 & $\mathbf{0 , 8 8}$ & $-0,70$ & $\mathbf{0 , 8 8}$ & 1 \\
\hline
\end{tabular}

Nota: NE: número de estratos; ADO: altura do dossel; AE: altura dos estratos; CE: cobertura do dossel; LI: lianas; EP: epífitas; G: gramíneas; AD: amplitude diamétrica; DAP: diâmetro à altura do peito. Matriz de correlação de dados de Pearson; nível de significância 95\%; em negrito estão as variáveis correlacionadas, sendo que quanto mais próximo de 1,0, maior a correlação; valores negativos indicam que quanto maior uma variável, menor a outra, enquanto que valores positivos indicam que quanto maior uma variável, maior a outra.

As gramíneas apresentaram uma correlação negativa com altura do dossel (-0,57), cobertura do quarto estrato $(-0,78)$ e lianas $(-0,68)$. Portanto, com a diminuição da altura do dossel, da altura e da cobertura dos estratos superiores, aumenta a entrada de luz, que proporciona o crescimento das gramíneas. Elas tornam-se invasoras no primeiro estrato, entremeadas por inúmeros caraguatás (bromeliáceas), aspecto característico nas Florestas Ombrófilas Densas Montana de porte baixo, Altomontana e Altomontana de porte baixo, aliado a uma espessa serapilheira, chegando a formar horizonte hístico, característico dos Organossolos.

Outra característica observada nessas formações é a inclinação das árvores mais antigas e de maior porte, devido aos processos de solifluxão e rastejamento do solo. As árvores são tortuosas e as epífitas cobrem seus os troncos, predominando avasculares, enquanto que nas formações Submontana e Submontana transição Montana as árvores são eretas e as epífitas predominantes são vasculares. 
Na tabela 5 verificam-se as variáveis observadas (solos, vegetação, declividade, posição no relevo, geologia e altitude) em campo e ainda a contribuição (peso), autovalor, porcentagem da variância e acumulada de cada variável para cada componente principal. Segundo Mingoti (2007), valores próximos a zero não são significativos, e o maior valor indica a variável mais importante da componente, sendo que os valores negativos são opostos aos positivos. Sabe-se que um dos objetivos da análise das componentes principais é a redução do número de variáveis, com cada componente principal agrupando variáveis correlacionadas, sendo que a variável mais importante representa as demais e quanto maior o autovalor, mais importante é a componente.

Tabela 5. Peso das variáveis, autovalor, porcentagem de variância, porcentagem acumulada por componente principal, relacionando os solos e a vegetação com o relevo, a altitude e a geologia na trilha Via Noroeste, Parque Estadual Pico do Marumbi.

Table 5. Variables weight, eigenvalue, percent of variance, cumulative percentage by the principals components, associating soils and vegetation to relief, altitude and geology at Via Noroeste trail, Pico do Marumbi State Park.

\begin{tabular}{|c|c|c|c|c|c|c|c|}
\hline \multirow{2}{*}{ Variável } & \multicolumn{7}{|c|}{ Componente } \\
\hline & 1 & 2 & 3 & 4 & 5 & 6 & 7 \\
\hline Floresta Ombrófila Densa Submontana & $-0,10$ & $-0,39$ & 0,19 & 0,07 & 0,11 & 0,06 & 0,34 \\
\hline $\begin{array}{l}\text { Floresta Ombrófila Densa Submontana transição } \\
\text { Montana }\end{array}$ & $-0,13$ & $-0,03$ & $-0,48$ & $-0,03$ & $-0,29$ & 0,10 & 0,13 \\
\hline Floresta Ombrófila Densa Montana & $-0,13$ & 0,08 & 0,22 & 0,05 & $-0,49$ & 0,03 & $-0,37$ \\
\hline Floresta Ombrófila Densa Altomontana & $-0,20$ & 0,19 & $-0,03$ & $-0,15$ & 0,40 & $-0,35$ & $-0,29$ \\
\hline Floresta Ombrófila Densa Altomontana de porte baixo & $\mathbf{0 , 3 8}$ & 0,20 & $-0,01$ & 0,04 & 0,02 & 0,14 & 0,03 \\
\hline Organossolos & 0,29 & 0,13 & 0,00 & $-0,25$ & 0,05 & 0,43 & $-0,20$ \\
\hline Neossolos & $-0,35$ & 0,13 & $-0,05$ & 0,37 & $-0,04$ & $-0,02$ & $-0,12$ \\
\hline Cambissolos & 0,00 & $-0,40$ & 0,08 & $-0,25$ & 0,14 & $-0,07$ & 0,11 \\
\hline Argissolos & 0,20 & 0,10 & $-0,01$ & 0,05 & $-0,18$ & $-0,54$ & 0,38 \\
\hline Pedregosidade & $-0,31$ & 0,18 & 0,29 & $-0,12$ & $-0,20$ & 0,01 & 0,06 \\
\hline Rochosidade & $-0,17$ & 0,18 & 0,03 & $-0,13$ & 0,19 & 0,54 & 0,20 \\
\hline Crista & 0,34 & 0,19 & 0,03 & $-0,15$ & $-0,13$ & $-0,04$ & 0,28 \\
\hline Encosta côncava & $-0,31$ & 0,18 & 0,29 & $-0,11$ & $-0,20$ & 0,01 & 0,06 \\
\hline Encosta convexa & 0,00 & $-0,01$ & 0,01 & 0,63 & 0,24 & 0,17 & 0,13 \\
\hline Encosta retilínea & $-0,03$ & $-0,31$ & $-0,29$ & $-0,23$ & 0,11 & $-0,10$ & $-0,39$ \\
\hline Cone detrítico & $-0,13$ & $-0,03$ & $-0,48$ & $-0,03$ & $-0,29$ & 0,10 & 0,13 \\
\hline Granito & 0,27 & $-0,18$ & 0,33 & 0,21 & $-0,04$ & 0,00 & $-0,25$ \\
\hline Dique de diabásio & $-0,23$ & 0,26 & 0,04 & $-0,25$ & 0,34 & $-0,09$ & 0,22 \\
\hline Declividade & 0,01 & 0,28 & $-0,28$ & 0,27 & 0,20 & $-0,07$ & $-0,10$ \\
\hline Altitude & 0,22 & $\mathbf{0 , 4 0}$ & 0,01 & $-0,07$ & 0,00 & $-0,11$ & $-0,09$ \\
\hline Autovalor & 4,91 & 4,09 & 3,15 & 1,98 & 1,70 & 1,59 & 1,11 \\
\hline Porcentagem da variância & 24,55 & 20,43 & 15,76 & 9,88 & 8,52 & 7,94 & 5,55 \\
\hline Porcentagem acumulada & 24,55 & 44,98 & 60,74 & 70,61 & 79,13 & 87,07 & 92,62 \\
\hline
\end{tabular}

Nota: em negrito, as variáveis mais importantes; valores negativos são opostos aos positivos.

Foram, portanto, extraídas 7 componentes principais a partir da matriz de dados referente às variáveis observadas (Tabela 5), sendo que, unidas, explicam 93\% da variabilidade das características observadas, das quais a primeira componente, que é a mais importante (maior autovalor), explica sozinha $24 \%$ da variabilidade, sendo sua variável mais importante a Floresta Ombrófila Densa Altomontana de porte baixo, representando as situações de sua ocorrência.

A segunda componente explica $20 \%$ da variabilidade dos dados, sendo a altitude sua variável de maior importância. Já a terceira componente explica $16 \%$ e tem como variável mais importante o cone detrítico em oposição ao granito.A quarta componente explica $10 \%$ da variabilidade, sendo a encosta convexa a variável de maior peso em oposição às demais situações de relevo. Para a quinta componente principal, a qual explica 8,5\% da variabilidade encontrada, a variável mais importante é a Floresta Ombrófila Densa Montana e a Floresta Ombrófila Densa Submontana transição Montana e os relevos de 
suas ocorrências, em oposição aos relevos de ocorrência de Floresta Ombrófila Densa Altomontana e Floresta Ombrófila Densa Submontana.

Para a sexta componente, a variável mais importante é o Argissolo, o qual representa a vegetação que ocorre sobre ele, em oposição aos Organossolos e sua respectiva cobertura vegetal. Esta componente explica $8 \%$ da variabilidade encontrada na trilha.

A sétima componente principal explica $5,5 \%$ da variabilidade observada, sendo a sua variável mais importante a encosta retilínea, que representa o material geológico que a define, os solos e a vegetação que sobre ela se desenvolveu, em oposição à crista e à encosta convexa e seus respectivos materiais geológicos e consequentes solos e vegetação.

Observando a figura 3, verificam-se as correlações entre os solos e a vegetação com o relevo, a altitude, o material geológico e a altitude. Os Organossolos e o Argissolo estão correlacionados principalmente à Floresta Ombrófila Densa Altomontana de porte baixo, e são encontrados nas maiores altitudes, em crista sobre granito, estando ainda correlacionados com declividade acentuada.

Os Neossolos estão altamente correlacionados com encosta côncava e dique de diabásio, onde há elevada pedregosidade e rochosidade e acentuada declividade. A essas situações está correlacionada principalmente a Floresta Ombrófila Densa Altomontana, enquanto que a Floresta Ombrófila Densa Montana está correlacionada com a encosta convexa e a Floresta Ombrófila Densa Submontana transição Montana com o cone detrítico. Já os Cambissolos estão correlacionados com a Floresta Ombrófila Densa Submontana em encosta retilínea nas menores altitudes e declividades.

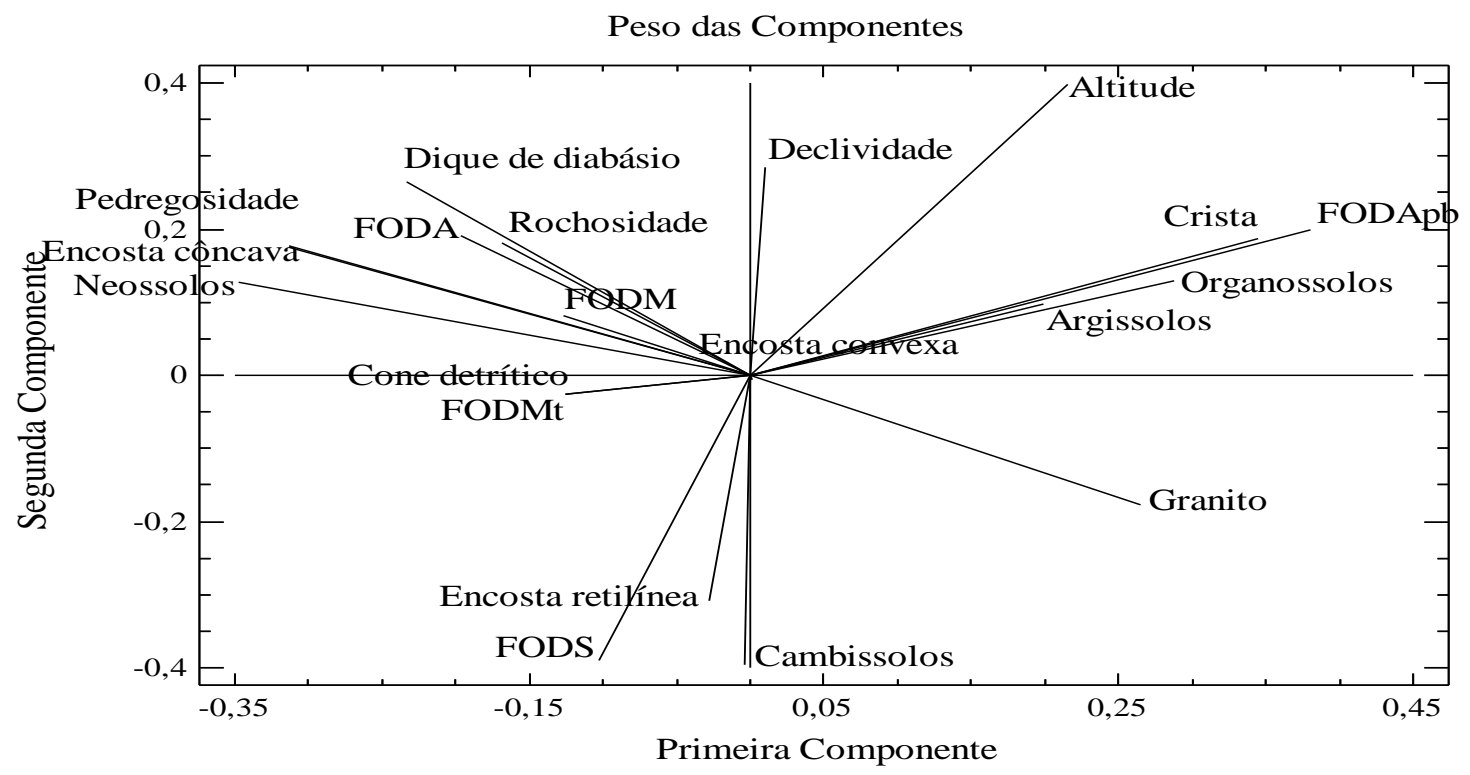

Figura 3. Análise das componentes principais, relacionando os solos e a vegetação com o relevo, a altitude e a geologia na trilha Via Noroeste, Parque Estadual Pico do Marumbi.

Figure 3. Principal components analysis, associating soils and vegetation to relief, altitude and geology at Via Noroeste trail, Pico do Marumbi State Park.

Nota: FODS: Floresta Ombrófila Densa Submontana; FODMt: Floresta Ombrófila Densa Submontana transição Montana; FODM: Floresta Ombrófila Densa Montana; FODA: Floresta Ombrófila Densa Altomontana; FODA pb: Floresta Ombrófila Densa Altomontana de porte baixo.

\section{CONCLUSÕES}

- Conclui-se que os solos presentes na trilha Via Noroeste pertencem às classes dos Cambissolos, Argissolos, Neossolos e Organossolos, os quais são extremamente ácidos, com baixa fertilidade e altos teores de alumínio. 
- Quanto à vegetação, a trilha é coberta pela Floresta Ombrófila Densa, subdividida nas formações Submontana, Submontana transição Montana, Montana, Montana de porte baixo, Altomontana e Altomontana de porte baixo, conforme o porte das espécies arbóreas.

- Quanto à hipótese desta pesquisa, conclui-se que a altitude e a declividade definem os solos e a vegetação de acordo com a posição no relevo, sendo que o aumento da altitude determina o acúmulo da matéria orgânica, enquanto que o aumento da declividade determina a perda de sedimentos, e ambos determinam a diminuição do porte arbóreo. As porções mais dissecadas, também, definem uma vegetação de menor porte.

\section{AGRADECIMENTOS}

Ao Instituto Ambiental do Paraná. À administração do Parque Estadual do Pico Marumbi. Ao pesquisador Gustavo Ribas Curcio. Aos amigos e colegas, Paulo César Brites, Ednilson Feola, Rogério Melo, Marcelo Brotto, Marcelo Scipione e Eduardo Lozano.

\section{REFERÊNCIAS}

BENITES, V. M.; CUNHA, T. J. F.; FERRAZ, R. P. D.; CAIAFA, A. N.; SIMAS, F. N.; MENDONÇA, E. S. Caracterização dos solos em duas topossequências sobre diferentes litologias em áreas altimontanas na Serra da Mantiqueira. Rio de Janeiro: Embrapa Solos, 2003. (Embrapa Solos. Documentos, 57).

BLUM, C. T. A Floresta Ombrófila Densa na Serra da Prata, Parque Nacional Saint-Hilaire/Lange, PR - Caracterização Florística, Fitossociológica e Ambiental de um Gradiente Altitudinal. 185 f. Dissertação (Mestrado em Engenharia Florestal) - Setor de Ciências Agrárias, Universidade Federal do Paraná. Curitiba, PR, 2006.

CORDANI, V. G.; GIRARDI, V. A. V. Geologia da folha de Morretes. Boletim da Universidade Federal do Paraná. Geologia n. 26. Curitiba: Instituto de Geologia da Universidade Federal do Paraná, 1967. $40 \mathrm{p}$.

DIAS, H. C. T.; SCHAEFER, C. E. G. R.; FERNANDES FILHO, E. I.; OLIVEIRA, A. P.; MICHEL, R. F. M.; LEMOS JÚNIOR, R. J. B. Caracterização de solos altimontanos em dois transectos no parque estadual do Ibitipoca (MG). Revista Brasileira de Ciência do Solo, v. 27, n. 3, p. 469 - 491, 2003.

EMPRESA BRASILEIRA DE PESQUISAS AGROPECUÁRIAS (EMBRAPA). Sistema brasileiro de classificação de solos. 2 ed. Rio de Janeiro: Centro Nacional de Pesquisa de Solos, 2006. 306 p.

Manual de métodos de análise de solo. 2 ed. Rio de Janeiro: Centro Nacional de Pesquisa de Solos, 2011. $230 \mathrm{p}$.

GHANI, N. L. B. Caracterização morfológica, física, química, mineralógica, gênese e classificação de solos altimontanos derivados de riólito e migmatito da Serra do Mar, PR. 197 f. Dissertação (Mestrado em Agronomia) - Setor de Ciências Agrárias, Universidade Federal do Paraná. Curitiba, 1996.

INSTITUTO AGRONÔMICO DO PARANÁ (IAPAR). Manual de análise química de solo. Londrina: Instituto Agronômico do Paraná. 1991.

Cartas Climáticas do Estado do Paraná. Acesso: <http://www.iapar.br/modules/conteudo/ conteudo.php?Conteudo =597>. Acesso em: 08/03/2012.

Manual técnico da vegetação brasileira. Rio de Janeiro: Diretoria de Geociências. Departamento de Recursos Naturais e Estudos Ambientais, 1992. 92 p.

MARQUES, R.; MOTTA, A. C. V. Análise química do solo para fins de fertilidade. In LIMA, M. R. (Org.). Manual de diagnóstico da fertilidade e manejo dos solos agrícolas. UFPR, Curitiba, 2003. p. $81-102$. 
MINGOTI, S. A. Análise de dados através de métodos de estatística multivariada: uma abordagem aplicada. Belo Horizonte: Editora UFMG, 2007. 297 p.

PARANÁ - CASA CIVIL. Decreto estadual n. 7.300, de setembro de 1990, que cria o Parque Estadual Pico do Marumbi. Curitiba: Casa Civil. 1990.

Decreto estadual n. 1.531, de novembro de 2007, que amplia a área do Parque Estadual Pico do Marumbi. Curitiba: Casa Civil. 2007.

RODERJAN, C. V. O gradiente floresta ombrófila densa altomontana do morro do Anhangava, Quatro Barras, PR - Aspectos climáticos, pedológicos e fitossociológicos. 119 f. Tese (Doutorado em Engenharia Florestal) - Setor de Ciências Agrárias, Universidade Federal do Paraná. Curitiba, 1994.

ROSSI, M.; QUEIROZ NETO, J. P. de. Relações solo/paisagem em regiões tropicais úmidas: o exemplo da Serra do Mar em São Paulo, Brasil. Revista do Departamento de Geografia, v. 14, p. 11 - 23, 2001.

SANTOS, R. D.; LEMOS, R. C.; SANTOS, H. G.; KER, J. C.; ANJOS, L. H. C. Manual de descrição e coleta de solo no campo. 5. ed. Viçosa: SBCS, 2005. 92 p.

SCHEER, M. B.; CURCIO, G. R.; RODERJAN, C. V. Funcionalidades ambientais de solos altomontanos na Serra da Igreja, Paraná. Revista Brasileira de Ciência do Solo, n. 35, p. 1113 - 1126, 2011.

SECRETARIA DE ESTADO DO MEIO AMBIENTE E RECURSOS HÍDRICOS (SEMA). Plano de manejo do Parque Estadual Pico do Marumbi. Curitiba: Instituto Ambiental do Paraná - IAP, 1996. $128 \mathrm{p}$.

. Mapeamento da Floresta Atlântica do Estado do Paraná. Curitiba: Secretaria de Estado do Meio Ambiente e Recursos Hídricos. 2002, 2 CD-ROM.

VASHCHENKO, Y.; PIOVESAN, R. P.; LIMA, M. R.; FAVARETTO, N. Solos e vegetação dos picos Camacuã, Camapuã e Tucum, Campina Grande do Sul, PR. Scientia Agraria, Curitiba, v. 8, n. 4, p. 411 - 419, 2007.

VASHCHENKO, Y.; BIONDI, D.; FAVARETTO, N. Erosão causada pela prática do montanhismo na trilha para os picos Camapuã e Tucum, Campina Grande do Sul (PR). Floresta, Curitiba, v. 38, n. 1, p. 71 - 85, 2008. 
